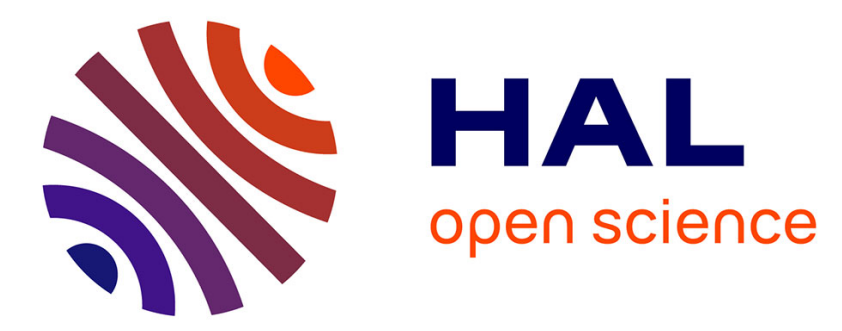

\title{
EuIII Luminescence in a Hygroscopic Ionic Liquid: Effect of Water and Evidence for a Complexation Process
}

Isabelle Billard, Soufiane Mekki, Clotilde Gaillard, Peter Hesemann, Gilles Moutiers, Clarisse Mariet, Alexandre Labet, Jean-Claude G. Bunzli

\section{To cite this version:}

Isabelle Billard, Soufiane Mekki, Clotilde Gaillard, Peter Hesemann, Gilles Moutiers, et al.. EuIII Luminescence in a Hygroscopic Ionic Liquid: Effect of Water and Evidence for a Complexation Process. European Journal of Inorganic Chemistry, 2004, 2004 (6), pp.1190-1197. 10.1002/ejic.200300588 . hal-02271937

\section{HAL Id: hal-02271937 \\ https://hal.science/hal-02271937}

Submitted on 8 Jun 2021

HAL is a multi-disciplinary open access archive for the deposit and dissemination of scientific research documents, whether they are published or not. The documents may come from teaching and research institutions in France or abroad, or from public or private research centers.
L'archive ouverte pluridisciplinaire HAL, est destinée au dépôt et à la diffusion de documents scientifiques de niveau recherche, publiés ou non, émanant des établissements d'enseignement et de recherche français ou étrangers, des laboratoires publics ou privés. 
Eu(III) Luminescence in an Hygroscopic Ionic Liquid: Effect of Water and Evidence for a Complexation Process

Isabelle Billard $^{*[a]}$, Soufiane Mekki ${ }^{[a]}$, Clotilde Gaillard ${ }^{[a]}$, Peter Hesemann ${ }^{*[b]}$, Gilles Moutiers $^{*[\mathrm{c}]}$, Clarisse Mariet ${ }^{[\mathrm{c}]}$, Alexandre Labet ${ }^{[\mathrm{c}]}$, and Jean-Claude G. Bünzli*[d]

${ }^{[\mathrm{a}]}$ IReS, Chimie Nucléaire, B. P. 28, 67037, Strasbourg Cedex 2, France

${ }^{[b]}$ CNRS UMR 5076, Hétérochimie Moléculaire et Macromoléculaire, Laboratoire de Chimie Organométallique, 8, rue de l'Ecole Normale, 34296 Montpellier Cedex 05, France

${ }^{[c]}$ CEA Saclay, INSTN/UECCC, 91191 Gif-sur-Yvette, France

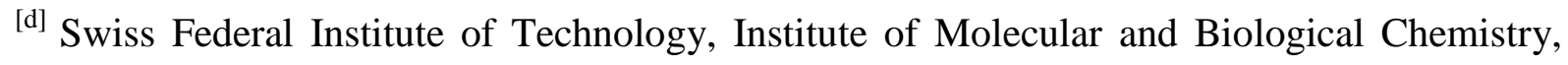
Laboratory of Lanthanide Supramolecular Chemistry, BCH 1402, CH-1015 Lausanne, Switzerland

Emails : isabelle.billard@ires.in2p3.fr ; gilles.moutiers@cea.fr; hesemann@cit.enscm.fr; jean-claude.bunzli@epfl.ch

Keywords: Ionic Liquids/ Eu(III) / Luminescence / Complexation

The spectroscopic characteristics (excitation, emission and lifetime) of Eu(III) dissolved in 1methyl-3-butylimidazolium bistrifluoromethanesulfonimide $\left(\right.$ BumimTf $\left._{2} \mathrm{~N}\right)$ are reported. In a first series of experiments, the effect of the presence of water in $\operatorname{BumimTf}_{2} \mathrm{~N}$ is examined. It appears that non-degassed solutions are most probably inhomogeneous, displaying large water clusters leading to an intense diffusion of the red light of a He:Ne laser. In these samples, the $\mathrm{Eu}$ emission spectrum is close to the one observed in slightly acidic aqueous solutions. When the samples are degassed, by contrast, the solution appears homogeneous and water is to be considered as a competitive ligand for the first coordination sphere of Eu. In a subsequent series of experiments, tetrabutylammonium chloride ( $\mathrm{TBACl}$ ) is added to the solution and the resulting species investigated. The ensuing enhancement in the metal-centred luminescence is interpreted in terms of changes in the inner-coordination sphere of the Eu(III) ion and possible structures are discussed.

\section{Introduction}


Room temperature ionic liquids (RTIL) appear as "multi-purpose liquids" able to replace usual organic solvents in almost every field of chemistry (e.g. catalysis, synthesis, electrochemistry). ${ }^{1}$ Both the cationic and the anionic components of these liquids can be easily varied, and they can therefore be tailored for particular applications or for specific sets of properties. As a consequence, RTIL's represent a green alternative to volatile organic solvents, offering environmentally safe processes.

In particular, in the field of nuclear waste reprocessing, there is still a need for improved routes for the actinide/lanthanide separation/extraction. In addition to promising studies on the use of ionic liquids for liquid/liquid extraction, ${ }^{2}$ a recent study has shown that some ionic liquids display reasonable stability under $\alpha$ and $\gamma$ irradiation, ${ }^{3}$ thus reinforcing their potential interest for the nuclear fuel industry. However, despite the increasing number of publications devoted to ionic liquids, the solvation effects, the solute-solvent and solventsolvent interactions as well as the general structural organization of these solvents are still hardly known. These fundamental aspects are of tremendous importance to the understanding of the solvating properties of these new solvents, thus limiting their applications for liquid/liquid extraction. In order to gain better insight into these questions, we have undertaken a spectroscopic investigation on the solvation of Eu(III) in 1-methyl-3butylimidazolium bistrifluoromethanesulfonimide $\left(\operatorname{BumimTf}_{2} \mathrm{~N}\right.$, see scheme 1). This ionic liquid has been chosen because it can be used, among others, for biphasic separations such as liquid extraction, due to its hydrophobic properties. Eu(III) has been chosen as representative of lanthanide ions and as a good homologue of Am(III), an actinide of great concern in the nuclear fuel cycle. In this work, we take advantage of the specific properties of Eu(III) to investigate its solvation in BuminTf $f_{2} \mathrm{~N}$ by means of luminescence measurements. Specific attention is paid to the role of water (considered as a solute) onto the luminescence properties of $\mathrm{Eu}(\mathrm{III})$ and the effect of added tetrabutylammonium chloride is also investigated.

\section{Results and discussion}

Synthesis of BumimTf ${ }_{2} \mathbf{N}$ and experimental methods: All chemicals were of the best reagent grades (Aldrich) and were used without further purification. All aqueous solutions were prepared with de-ionized water (Millipore deionization system, $\omega=18.3{\mathrm{M} \Omega ~ \mathrm{~cm}^{-1}}^{\text {) }}$.

The synthesis of BumimTf ${ }_{2} \mathrm{~N}$ is derived from the previously reported synthesis of BumimPF ${ }_{6}^{4}$ and is typically performed as described in the following. 
First step : synthesis of BumimCl. A three-necked round bottomed flask under argon, equipped with a water refrigerant was loaded with methylimidazole (1 mole, $82.11 \mathrm{~g})$ and of n-chlorobutane ( 1 mole, $92.57 \mathrm{~g}$ ). The mixture was stirred under argon for $48 \mathrm{~h}$ at $70^{\circ} \mathrm{C}$, until appearance of a pale yellow viscous mixture. It was then transferred into a flask and stored at $3-5^{\circ} \mathrm{C}$ under argon until quantitative precipitation $(\approx 12 \mathrm{~h})$. White crystals were obtained which were washed several times with ethyl acetate and filtered each time on a Büchner apparatus. They were transferred into a dry box containing phosphorus pentoxide and set under vacuum. A fine white powder of BumimCl was obtained with typical yields of $\approx 80 \%$. Second step : Synthesis of BumimTf ${ }_{2} N$. A solution of BumimCl $(110 \mathrm{~g})$ in water $(150 \mathrm{~mL})$ was added to a solution of $\operatorname{LiTf}_{2} \mathrm{~N}(200 \mathrm{~g})$ in water $(300 \mathrm{~mL})$ and the resulting mixture was stirred at $70^{\circ} \mathrm{C}$ for $16 \mathrm{~h}$. Two phases were obtained and the upper one (aqueous phase) was decanted. The bottom phase $\left(\right.$ BumimTf $\left._{2} \mathrm{~N}\right)$ was washed several times with de-ionized water $(10 \times 350$ $\mathrm{mL}$ ). BumimTf $\mathrm{f}_{2} \mathrm{~N}$, as a transparent, slightly viscous liquid, was transferred and stored in a dry box under vacuum containing phosphorus pentoxide. Typical yields: $\approx 80 \%$. The water content of the samples was determined by Karl Fischer titration, using standard procedures, a Mettler DL18 titrator, hydranal composite 5 (Fluka) and analytical grade methanol.

Absorption spectra in the range 190-900 nm were recorded on a Uvikon 930 (Kontron) spectrometer with 1-cm quartz cuvettes. In all cases, the reference was an empty quartz cuvette. No precaution was taken for the storage of the samples, that were simply left in the quartz cuvettes (with teflon cap), so that the water content may have changed with time (see the relevant study in the text).

Emission and excitation spectra were recorded on a classical spectrofluorimeter (Photon Technology International) which does not allow for time-resolution but is corrected for gain efficiency of the detector. Data are also presented as $\mathrm{R}_{612 / 589}$, the ratio of the intensity of the ${ }^{5} \mathrm{D}_{0} \rightarrow{ }^{7} \mathrm{~F}_{2}$ transition (around $612 \mathrm{~nm}$ ) over that of the ${ }^{5} \mathrm{D}_{0} \rightarrow{ }^{7} \mathrm{~F}_{1}$ transition (around 589 $\mathrm{nm}$ ) for an excitation at $\lambda_{\text {exc }}=394 \mathrm{~nm}$. The uncertainty on the value of $\mathrm{R}_{612 / 589}$ is in the range of $\pm 10 \%$. The time-resolved emission spectroscopy (TRES) apparatus has been described in details elsewhere. ${ }^{28,29}$ Briefly, for decay measurements, the excitation wavelength was set to $266 \mathrm{~nm}$. As is usual for time-resolved experiments of this kind, the data analysis was performed by systematically excluding the first 10 microseconds of each decay, in which the intense short-lived luminescence of the pure BumimTf ${ }_{2} \mathrm{~N}$ is dominating and thus precludes any detection of the long-lived europium species. Therefore, in the following, the discussion on the decay behavior only corresponds the lifetime ascribable to Eu(III). The importance of the decay behavior (either mono- or multiexponential) has been stressed in other papers ${ }^{26,30}$ and the quality of the fits was assessed both 
by the usual $\chi^{2}$ test and the shape of the residuals (experimental minus calculated values). The error on the lifetime values was on the order of $\pm 3 \%$. Although the measurements of the luminescence spectra and decays are easy to perform under the experimental conditions of this work, they cannot be conducted under optimum conditions for europium assays: for most of the feasible excitation wavelengths, the absorption of the sample was way above the usual 0.05 limit, for which a linear relationship holds between concentration and emission intensity, because of solvent absorption. All experiments were performed at a controlled temperature of 294 K. The data presented in Figs. 5-8 have been recorded immediately after the end of the degassing procedure.

\section{Purification and Characterization}

The purification procedure previously used for BumimPF$_{6}{ }^{4}$ was also applied to BumimTf ${ }_{2}$ N. However, the absorption band in the range $250-300 \mathrm{~nm}$, observed for nonpurified BumimPF${ }_{6}{ }^{4}$ is still present in the absorption spectrum of the purified BumimTf ${ }_{2} \mathrm{~N}$ (Fig. 1). It is probable that some organic impurities still remain. To our knowledge, the absorption spectrum of ultra-pure BumimTf ${ }_{2} \mathrm{~N}$ is not known, so that comparison with our batch is impossible. On the other hand, repeated recording of the absorption spectrum showed that the BumimTf ${ }_{2} \mathrm{~N}$ batch used in this work is stable for more than four months.

Due to the synthetic procedure, BumimTf ${ }_{2} \mathrm{~N}$ contains water, even after purification on an alumina column. The presence of water is a common feature of room-temperature ionic liquids $^{1,5-7}$ and numerous works have pinpointed the large influence of water on various physico-chemical properties of RTILs. ${ }^{8,9}$ This very important point will be addressed in this work.

\section{Water Contents and Dissolution of Salts in Bumim $\mathrm{Tf}_{2} \mathbf{N}$}

A previous study ${ }^{8}$ has focused on the effect of water onto the properties of various RTILs, such as BumimBF 4 or BumimPF 6 . In particular, it was shown that above a given water content (around a molar fraction of 0.5), the viscosity and the density of the resulting mixtures become water-like, so that these samples have to be considered as aqueous solutions of RTILs and not as hydrated RTILs. Another study has shown that water absorption by BumimTf ${ }_{2} \mathrm{~N}$ may be rapid and important. ${ }^{10}$ For the BumimTf ${ }_{2} \mathrm{~N}$ batch used in this work, the amount of water was equal to $(5000 \pm 50) \mathrm{ppm}$ (i.e. $0.4 \mathrm{M}$ or $0.5 \% \mathrm{w} / \mathrm{w})$ after purification. This is a consequence of the numerous water washes at the end of the synthesis and the subsequent purification on the alumina column. This batch is thus not water-saturated, as compared to values up to $14000 \mathrm{ppm}$ reported in the literature for BumimTf $\mathrm{f}_{2} \mathrm{~N},{ }^{1}$ but nevertheless contains a substantial amount of water. After several months of storage, the water content did not change 
as shown by a new determination leading to $(5100 \pm 500) \mathrm{ppm}$. In order to control the water content of the samples, we have degassed them according to two different methods. In procedure I, batches of $5 \mathrm{~mL}$ were pumped at room temperature during $18 \mathrm{~h}$ and, additionally, at $50{ }^{\circ} \mathrm{C}$ during $10 \mathrm{~h}$ (residual pressure: $1.8 \mathrm{mbar}$ ); the resulting water content was below 100 ppm (i.e. $8 \times 10^{-3} \mathrm{M}$ or $0.01 \% \mathrm{w} / \mathrm{w}$ ). In few cases (see below), samples have been further degassed during $48 \mathrm{~h}$ at $70{ }^{\circ} \mathrm{C}$ (procedure II). Finally, a solution of europium triflate has been degassed (procedure I) directly in a quartz cuvette connected to the degassing setup by a quartz-glass tube. In this case, by use of a tap, the solution in the cuvette is air- and watertight but, due to the bulkiness of the setup, only lifetime measurements could be performed.

Europium(III) triflate (Aldrich), tetrabutylammonium chloride (Aldrich) and triflate (Aldrich), and $\mathrm{NaCl}$ (Prolabo) were used as received. Hygroscopic salts were kept in a dessicator with $\mathrm{P}_{4} \mathrm{O}_{10}$. Unless otherwise specified, the europium concentration was $5 \times 10^{-3} \mathrm{M}$. Possible changes in density from one sample to another due to different water contents have not been considered for the determination of the concentration. A common value $d=1.43$ for the density (non-degassed BumimTf ${ }_{2} \mathrm{~N}$ ) has been considered for all the BumimTf ${ }_{2} \mathrm{~N}$ samples of this work. Even considering that the europium triflate salt contains 4 water molecules per europium unit, the amount of water introduced with the salt is negligible compared with the water already present in the non-degassed solvent.

Upon addition of europium triflate to $\operatorname{BumimTf}_{2} \mathrm{~N}$, a slightly cloudy solution was obtained, which indicates either an incomplete dissolution or, more probably, the formation of inhomogeneous clusters. As a matter of fact, these samples strongly diffuse the red light of a He:Ne laser. On the other hand, light diffusion is no more observed after degassing the samples using procedure I (solutions become clear) or II, so that these samples may be considered as being homogeneous (see also discussion below).

Various amounts of tetrabutylammonium chloride together with europium triflate $(r=$ $[\mathrm{TBACl}] /[\mathrm{Eu}(\mathrm{III})]=3$ to 9) have been introduced in BumimTf ${ }_{2} \mathrm{~N}$. Due to the very slow kinetics of dissolution, a small amount of $\mathrm{CH}_{3} \mathrm{CN}$ (on the order of $0.5 \mathrm{~mL}$ ), which is totally miscible in BumimTf ${ }_{2} \mathrm{~N}$, has been added to the BumimTf ${ }_{2} \mathrm{~N}$ solutions, prior to degassing, in order to speed up the process. Considering the vapor pressure of $\mathrm{CH}_{3} \mathrm{CN}$, it can be safely assessed that all of it is removed at the end of the degassing procedure. Despite this modified dissolution procedure, not all the salts dissolve for $r<4.5$, even after degassing (procedure I). No attempts were made to determine the exact composition of the un-dissolved residue. For $r$ $\geq 4.5$, the dissolution is fully achieved after degassing. Finally, a single solution of europium 
triflate with tetrabutylammonium triflate (TBA-triflate, $r=6$ ) has been prepared and degassed.

\section{Effect of Water on the Spectroscopic Characteristics of Eu(III)}

Results: Europium triflate $5 \times 10^{-3} \mathrm{M}$ in BumimTf $_{2} \mathrm{~N}$ turns to a slight brownish color after degassing (procedure II) and a very weak absorption band located at $394 \mathrm{~nm}$ can be observed, which corresponds to the transition with the largest oscillator strength in the Eu ${ }^{\mathrm{III}}$ spectrum, ${ }^{5} \mathrm{~L}_{6} \leftarrow{ }^{7} \mathrm{~F}_{0,1}$. The spectrum of a more concentrated and degassed solution $\left(4 \times 10^{-2} \mathrm{M}\right)$ is displayed on Figure 2, from which a molar absorption coefficient of $0.8 \mathrm{M}^{-1} \mathrm{~cm}^{-1}(\lambda=394 \mathrm{~nm})$ could be estimated. This value is of the same order of magnitude than the one reported for $\mathrm{Eu}^{\text {III }}(\mathrm{aq}): 2.4 \mathrm{M}^{-1} \mathrm{~cm}^{-1} .{ }^{11}$ In two previous works, ${ }^{12,}{ }^{13}$ some lanthanide triflates have been dissolved in RTILs, in particular in $\mathrm{BumimPF}_{6}$, at concentrations far below the maximum concentration obtained by us. This may be due in part to the use, in these studies, of anhydrous lanthanide salts.

RTILs are known to be hygroscopic ${ }^{1,7,8}$ and previous studies have given insight into the dependence of the kinetics of water absorption by RTILs upon experimental conditions. ${ }^{7,8 \text {, }}$ ${ }^{10}$ In order to get a deeper understanding of the influence of water on europium luminescence in BumimTf $f_{2} \mathrm{~N}$, a solution has been submitted to cycles combining degassing procedures and storage durations during which solutions were kept in the quartz cuvette, with a teflon cap. Table I summarizes this cycle and displays the decay behavior (either mono- or biexponential), the corresponding lifetimes and relative intensities during the cycle. In this Table, $\mathrm{t}=0$ corresponds to the end of the first degassing procedure and positive $\mathrm{t}$ values indicate the time elapsed since $\mathrm{t}=0$, at which the data (decay profile and emission/excitation spectra) have been recorded. By definition, the notation $t=-1$ means that the measurement has been performed before this first degassing procedure, when the ionic liquid water content was constant whith time (see section "water contents"). Note that a lifetime decay could be obtained for the non-degassed (probably heterogeneous) sample, as no fluctuations of the luminescence intensity were observed. Fig. 3 presents the excitation spectra obtained at times equal to $-1,0$, and 13 days of the cycle, while emission spectra are displayed on two separate figures (Figs. 4a, b) in view of the large differences in emission intensities. For $t=25$ days, the excitation and emission spectra are very similar to those for $t=13$ days and are therefore not shown.

For all samples, the excitation spectra essentially display f-f transitions, indicating no antenna effect from the ionic liquid: Réponse 3 ème referee sur effet d'antenne quand même 
un peu présent ? The energy of these transitions does not vary, contrary to their intensities which substantially decrease over time after the first degassing procedure. A similar behavior is observed for the emission spectra and lifetimes. Through excitation at other wavelengths (data not shown), the emission is similar in shape and the intensity change reflects the relative intensities observed in the excitation spectra. Lifetimes exhibit a peculiar behaviour: a single exponential decay is measured for the non-degassed solution, with a short lifetime of 0.159 ms, which becomes bi-exponential upon degassing, with much longer lifetimes of 0.64 and $1.6 \mathrm{~ms}$. After six days of storage, the decay is again characterized by a single exponential, but turns again bi-exponential after the second degassing, and so on. For the air- and water- tight solution, a bi-exponential behavior is still observed more than twelve days after degassing and the lifetime values are perfectly stable.

Discussion: The intense diffusion of the He:Ne laser light in the non-degassed europium solution, while diffusion is almost zero for pure non-degassed $\operatorname{BumimTf}_{2} \mathrm{~N}$, points to the presence of large aggregates (clusters) in this solution, so that the non-degassed europium solution, which contains approximately $80 \mathrm{H}_{2} \mathrm{O}$ molecules per Eu ${ }^{\mathrm{III}}$ ion, should be better considered as being an emulsion. The emission spectrum of the non-degassed sample (Fig. 4a) is very similar to the one obtained for $\mathrm{Eu}^{3+}{ }_{\text {aq }}$ in slightly acidic aqueous solution, ${ }^{11,14}$ although the corresponding lifetime is larger $\left(0.159 \mathrm{~ms}\right.$ compared with $0.111 \mathrm{~ms}$ for $\mathrm{Eu}^{3+}$ aq, see Table I). The presence of high-energy $\mathrm{O}-\mathrm{H}$ oscillators in the inner coordination sphere of $\mathrm{Eu}^{\mathrm{III}}$ is known to induce a severe quenching of the luminescence. ${ }^{15}$ The short lifetime measured for the ionic liquid solution suggests that $\mathrm{Eu}^{\mathrm{III}}$ is heavily hydrated, possibly as much as in water. Indeed, triflate is only slightly more coordinating than perchlorate ${ }^{16}$ and should not bind to the $\mathrm{Eu}^{\mathrm{III}}$ ion in water. On the other hand, no data are available on the coordinating strength of $\mathrm{Tf}_{2} \mathrm{~N}^{-}$but since it is present in large excess in the solutions, inner-sphere coordination cannot be excluded. The longer lifetime measured in the RTIL can be due to the limited amount of water in BumimTf $f_{2} \mathrm{~N}$ leading to (i) a decreased inner-sphere hydration number $n$ and/or a decreased outer sphere hydration number $m$ in the $\left\{\left[\mathrm{Eu}\left(\mathrm{A}^{-}\right)_{x}\left(\mathrm{H}_{2} \mathrm{O}\right)_{n}\right]^{(3-x)+}\left(\mathrm{H}_{2} \mathrm{O}\right)_{m}\left(\mathrm{~A}^{-}\right)_{(3-x)}\right\}$ aggregates ( $\mathrm{A}^{-}$stands for an anion). In water, $n$ is fractional (and $x$ is essentially equal to zero), reflecting a fast equilibrium between 8 - and 9-coordinated species, ${ }^{17}$ and hexahydrated $\mathrm{Ln}^{\mathrm{III}}$ ions have been evidenced in the solid state. The contribution of second-sphere oscillators to the luminescence decay is not well known, but in the case of $\mathrm{Eu}^{\mathrm{III}}$ complexes with cyclen derivative, it has been estimated to be $0.25 \mathrm{~ms}^{-1}{ }^{18}$

By contrast, the degassed sample at the beginning of the cycle $(\mathrm{t}=0$ day) presents completely different $\mathrm{Eu}^{\mathrm{III}}$ spectroscopic properties, indicating a large loss of inner-sphere 
water molecules. This is illustrated by the increased intensity of the hypersensitive transition $\left({ }^{5} \mathrm{D}_{0} \rightarrow{ }^{7} \mathrm{~F}_{2}\right)$ at ca. $613 \mathrm{~nm}$ by a factor $>3$ (see Fig. $4 \mathrm{~b}$ ). The relative broadness of the bands and their lack of crystal-field fine structure may indicate that $\mathrm{Eu}^{\mathrm{III}}$ is imbedded into a medium with properties comparable to those of a glass. The degassing procedure drastically decreases the total water amount but some water remains: a water content of $50 \mathrm{ppm}$ still corresponds to one molecule of water per $\mathrm{Eu}^{\mathrm{III}}$ ion.

No information can be gained on which type of water, either already accommodated in the solvent prior solution preparation or introduced with the europium salt is better extracted in the degassing procedure. ${ }^{10}$ As a matter of fact, the absence of laser light diffusion after degassing is evidence for an homogeneous solution and the changes in the emission spectra show that europium is now solvated in the RTIL and no more in "water clusters". The biexponential behavior of the luminescence decay either in the air and water tight cuvette or at the beginning of the storage can be considered as reflecting the presence of two different Eu ${ }^{\text {III }}$ species in solution. One explanation could be the formation of inner-sphere complexes with the counterions:

$$
\begin{aligned}
& \left\{\left[\mathrm{Eu}\left(\mathrm{H}_{2} \mathrm{O}\right)_{n}\right]^{3+}\left(\mathrm{H}_{2} \mathrm{O}\right)_{m}\right\} \leftrightarrows\left[\mathrm{Eu}\left(\mathrm{H}_{2} \mathrm{O}\right)_{n}\right]^{3+}+m \mathrm{H}_{2} \mathrm{O} \leftrightarrows\left[\mathrm{Eu}\left(\mathrm{H}_{2} \mathrm{O}\right)_{x}\right]^{3+}+(m+n-x) \mathrm{H}_{2} \mathrm{O} \\
& {\left[\mathrm{Eu}\left(\mathrm{H}_{2} \mathrm{O}\right)_{x}\right]^{3+}+y \mathrm{~A}^{-} \leftrightarrows\left[\mathrm{Eu}(\mathrm{A})_{\mathrm{y}}\left(\mathrm{H}_{2} \mathrm{O}\right)_{x-y}\right]^{3+}+y \mathrm{H}_{2} \mathrm{O}}
\end{aligned}
$$

In equation (2), $\mathrm{A}^{-}$has been taken as being a monodentate anion, but the triflate could also be bidentate or even acts as bridging moiety. The latter assumption is, however, not too probable in view of the relatively high dilution of the solutions. In water, phenomenological calibration curves have been reported which relate the number of inner-sphere water molecules to the lifetimes measured in water and deuterated water. ${ }^{15,19}$ In absence of structural information on the solvated species in RTIL, and because these phenomenological correlations cannot be easily transposed from one solvent to another, no such relationship is available, therefore an estimate of $x$ is not within reach with the present lifetime data. We note, however, that $1.6 \mathrm{~ms}$ is a rather long lifetime (compare: $2.10 \mathrm{~ms}$ for $\mathrm{Eu}\left(\mathrm{ClO}_{4}\right)$ in anhydrous acetonitrile) ${ }^{21}$ and as the RTIL medium is not dielectrically too different from an organic solvent, the associated species probably contains, on average, less than one water molecule. The subsequent transformation of the decay into a single exponential curve, with a concomitant decrease in lifetime, after few days of storage, reflects a re-hydration of the $\mathrm{Eu}^{\mathrm{III}}$ ion, although not completely, since both the lifetime and the $\mathrm{R}_{612 / 589}$ ratio remain substantially larger than in the non-degassed solution. We interpret this in terms of several different hydrated species being in equilibrium: when several water molecules are coordinated in the inner sphere their lifetimes become comparable, rendering difficult a mathematical resolution of the decays. 
Moreover, fast water exchange reactions lead to an averaging of the species on the time scale of the luminescence experiment (ms).

After applying degassing procedure II, the solution contains again two Eu ${ }^{\mathrm{III}}$ species, one having a relatively short lifetime (which corresponds to the short lifetime measured after procedure I was applied), while the other features a much longer lifetime than the long lifetime of the previous sample. This clearly demonstrates that further dehydration has occurred. The value of this lifetime, $2.56 \mathrm{~ms}$, probably implies that a anhydrous species has been formed, but again, this statement will have to be checked by determining the exact nature of the species in solution. When re-hydration occurs, the decay turns again into a single exponential curve with a lifetime intermediate between the ones obtained after the first and the second degassing procedure.

The results presented above are of great practical interest and show that, for luminescence measurements, caution should be paid to the degassing procedure and to the water intake by the sample. However, it should be stressed that luminescence measurements can be performed with reasonable confidence (i. e. results are reproducible) because, as can be seen from Table I, the absorption of water under our experimental conditions is slow. This slow kinetics, as compared to that observed by Seddon and co-workers, ${ }^{8}$ or by Tran and coworkers $^{10}$ is mainly due to the absence of vigorous stirring and to the use of a cap for the cuvettes in our case.

\section{Spectroscopy in the Presence of Tetrabutylammonium Chloride (TBACl)}

Results: Figures 5 and 6 display the excitation and emission spectra for ratios $r=$ [TBACl]/[Eu] equal to 4.5, 6 and 9. As compared to Figures 3 and 4, the main difference is the strong band centered around $330 \mathrm{~nm}$ seen in the excitation spectra and the well-defined structure in the Eu emission spectra. As a comparison, a solution containing only $\mathrm{TBACl}$ in BumimTf ${ }_{2} \mathrm{~N}$ displays a single very broad band of very low intensity centred at $375 \mathrm{~nm}$.

The total excitation intensity decreases as a function of $r$, as the total emission intensity does. For all the samples, in contrast to what is obtained without $\mathrm{TBACl}$, the luminescence decays are single exponential curves, even after the degassing procedure. The $\mathrm{Eu}^{\mathrm{III}}$ lifetime values as a function of the total TBACl amount are displayed in Table II. Although incomplete dissolution occurs for $r<4.5$, a lifetime value could be obtained.

The excitation and emission spectra of the $\mathrm{Eu}(\mathrm{III}) / \mathrm{TBA}$-triflate/BumimTf ${ }_{2} \mathrm{~N}$ solution $(r=6)$ are displayed on Figures. 7 and 8, together with the data for TBACl, for the sake of comparison. Compared to the addition of chloride, the emission intensity is lower when the triflate is added and the bands are much broader. 
The effect of progressive water absorption by BumimTf $_{2} \mathrm{~N}$ as a function of time has also been studied. In the case of TBACl, and by contrast with the solutions to which no TBA salt is added, the increasing amount of water has no effect at all on the Eu ${ }^{\text {III }}$ lifetime and decay behavior for $r=9$, even after 22 days of storage: the lifetime changed by less than $10 \mu \mathrm{s}$. On the other hand, the lifetime of the solution to which TBA triflate has been added decreases as a function of time (from $\tau=1180 \mu$ s after degassing to $492 \mu$ s after three days of storage).

Discussion: There is no physical reason to state that the introduction of $\mathrm{TBACl}$ strongly modifies the course of the degassing procedure. Therefore, the single exponential behavior of the decays after the degassing procedure shows that the $\mathrm{Eu}^{\mathrm{III}}$ coordination sphere is strongly modified as compared with the solution without TBACl. This is also illustrated by the changes observed in the excitation and emission spectra as a function of $r$. In comparison with what is known on europium luminescence in other solvents, ${ }^{20-22}$ these changes are ascribed to a complexation process. Slight changes can be observed in the emission spectra at $r=3$ and $r$ $=9$, especially in the value of $\mathrm{R}_{612 / 589}$. This experimental fact, together with the reduced solubility observed for $r<4.5$ would indicate that at least two different complexes are present in solution, depending on the $r$ ratio. TBACl is a 1:1 electrolyte, but it is not clear from our experiments whether it is entirely dissociated in BumimTf $_{2} \mathrm{~N}$. Although a detailed symmetry analysis is not possible due to the relative broadness of the emission bands, we note that ${ }^{5} \mathrm{D}_{0} \rightarrow{ }^{7} \mathrm{~F}_{1}$ generates one symmetrical band while 2-3 components are seen for the ${ }^{5} \mathrm{D}_{0} \rightarrow{ }^{7} \mathrm{~F}_{2}$ transition, indicating a relatively high symmetry around the Eu ${ }^{\mathrm{III}}$ ion. Trivalent europium is known to form a stable hexachloride with elpasolite structure and $\mathrm{O}_{\mathrm{h}}$ symmetry. ${ }^{23}$ In solution in ethanol, this species either dissociates or reacts with the solvent to give a species with $D_{2}$ symmetry. ${ }^{24}$ It is noteworthy that the ${ }^{5} \mathrm{D}_{0} \rightarrow{ }^{7} \mathrm{~F}_{2}$ spectrum reported for the latter species is very similar to the one reported in Figure 6 for $r=6$ and so are the spectra for $\left[\mathrm{Cl}^{-}\right] /[\mathrm{Eu}]=26$ (in ethanol) ${ }^{24}$ and $r=9$ (Fig. 6). Therefore we may safely conclude that upon addition of TBACl, polychloro species form in RTIL solution.

The implications of a single exponential behavior of the decays, while the emission spectra and the lifetime values are changing as a function of the ligand concentration (TBACl case), have been discussed long ago ${ }^{25}$ and have been revisited recently. ${ }^{26}$ Both papers agree that such experimental facts point to a photochemically induced complexation reaction occurring in the solution. It is also agreed that the excitation and emission data collected for $r$ $=9$ (lifetime plateau value, see Table II) are those of the higher complex obtained with a lifetime of $2760 \mu \mathrm{s}$. 
The luminescence enhancement observed could be explained in two ways. (i) the interaction of chloride ions in the inner coordination sphere results in a ligand-to-metal transfer state reflected in the excitation spectrum (Fig. 7) and energy transfer takes place between this state and $\mathrm{Eu}{ }^{\mathrm{III}}$. Such a state is observed around $33000 \mathrm{~cm}^{-1} 27$ for $\left[\mathrm{EuCl}_{6}\right]^{3-}$ in the solid state and excitation in such states may result in metal-centered luminescence when they lie at relatively high energy, which is the case here. Moreover, the spectrum displayed on Fig. 8 (top) matches perfectly well the one published earlier for $\left[\mathrm{EuCl}_{6}\right]^{3-}$ in ethanol ${ }^{24}$. (ii) The inner-sphere chloride ions act as relay between the metal ion and the $\mathrm{Bumim}^{+}$or $\mathrm{TBA}^{+}$ cations in the second solvation shell, allowing a through-bond energy transfer.

Finally, the quite different spectroscopic properties observed upon addition of TBA triflate, in particular the absence of luminescence enhancement, point to a much weaker interaction between the added anions and the metal ion so that competition with water molecules easily leads to hydrated species with quenched luminescence.

\section{Conclusion}

For the first time, a spectroscopic investigation of $\mathrm{Eu}(\mathrm{III})$ dissolved in BumimTf $\mathrm{N}_{2} \mathrm{~N}$ has been conducted, particularly with respect to the effect of water and added TBA chloride. The results pinpoint the importance of degassing procedures and storage conditions, in view of the highly hygroscopic nature of the solvent. A complexation process between $\mathrm{Eu}(\mathrm{III})$ and the added TBA salts has been evidenced and some insight into the species in equilibrium and the composition of the inner coordination sphere of $\mathrm{Eu}(\mathrm{III})$ have been obtained. A first conclusion is that the behaviour of the $\mathrm{Eu}(\mathrm{III})$ ion in degassed BumimTf $\mathrm{B}_{2} \mathrm{~N}$ displays trends similar to the ones exhibited in other organic hygroscopic solvents (e.g. acetonitrile or ethanol), with respect to both its coordination and spectroscopic properties. On the other hand, non-degassed solutions present a highly inhomogeneous nature. In view of the evaluation of RTIL's for use in future lanthanide/actinide extraction processes it is essential that basic data on the solvation of metal ions in these liquids be at hand. From this standpoint, the results presented here are very encouraging since they demonstrate that complexation processes analogous to those in common solvents take place in the investigated RTIL, and that they can be monitored by a highly sensitive technique such as time-resolved luminescence. However, some differences have also been unraveled and we are now concentrating our efforts to gather structural data on 
these solutions in order to get a much deeper understanding of the nature of the solvated and complexed species in equilibrium.

\section{Acknowledgements}

This work has been performed with the financial help of the French "Groupement de Recherches" PARIS.

We thank Prof. K. R. Seddon for an interesting discussion about degassing procedures. The help of Dr. M. Roynette for the Karl Fischer measurements is greatly acknowledged. J.-C. G. B. is grateful to the Swiss National Science Foundation for financial support.

\section{Captions}

Table I : Decay behavior, lifetime values $(\mu \mathrm{s})$, relative intensities (\%) and $\mathrm{R}_{612 / 589}$ values for the Eu ${ }^{\text {III }}$-triflate salt in BumimTf $_{2} \mathrm{~N}$ along the degassing/storage cycle (see text).

Table II : Lifetime values for the solutions of the $\mathrm{Eu}^{\mathrm{III}}$-triflate salt containing added TBACl.

Figure 1 : Absorption spectrum of the BumimTf ${ }_{2} \mathrm{~N}$ batch used in this work (non degassed).

Figure 2 : absorption spectrum of the Eu ${ }^{\text {III }}$ triflate salt $4 \times 10^{-2} \mathrm{M}$ in BumimTf $_{2} \mathrm{~N}$.

Fig. 3: Excitation spectra of the Eu ${ }^{\mathrm{III}}$ triflate salt $5 \times 10^{-3} \mathrm{M}$ in BumimTf ${ }_{2} \mathrm{~N}$ during the degassing cycle. Emission wavelength : $\lambda=609 \mathrm{~nm}$. Solid line $: \mathrm{t}=-1$ day $;(-\square-): \mathrm{t}=0$ day (procedure I) $;(-+-): t=13$ days (procedure II).

Figure 4a : Emission of the Eu ${ }^{\text {III }}$ triflate salt $5 \times 10^{-3} \mathrm{M}$ in BumimTf $_{2} \mathrm{~N}$ at $\mathrm{t}=-1$ day $($ see text and Table I). Excitation wavelength $: \lambda=394 \mathrm{~nm}$.

Figure $4 \mathrm{~b}$ : Emission of the Eu ${ }^{\mathrm{III}}$ triflate salt $5 \times 10^{-3} \mathrm{M}$ in BumimTf $_{2} \mathrm{~N}$ in function of the degassing procedure (see text and Table I). Excitation wavelength $: \lambda=393 \mathrm{~nm}$. Solid line $: \mathrm{t}$ $=0$ day (procedure $\mathrm{I}) ;(\mathrm{o}): \mathrm{t}=13$ days (procedure II). 
Figure 5: Excitation of the Eu $\mathrm{Eu}^{\mathrm{III}}$ triflate salt $5 \times 10^{-3} \mathrm{M}$ in $\mathrm{BumimTf}_{2} \mathrm{~N}$ containing TBACl. Emission at $\lambda=608 \mathrm{~nm}$. Solid line $: \mathrm{r}=9 ;(-+-): \mathrm{r}=6 ;(\circ): \mathrm{r}=4.5$.

Figure 6: Emission of $\mathrm{Eu}^{\mathrm{III}}$ triflate salt $5 \times 10^{-3} \mathrm{M}$ in BumimTf $_{2} \mathrm{~N}$ containing $\mathrm{TBACl}$. Excitation wavelength $: \lambda=464 \mathrm{~nm}$. Solid line $: r=9 ;(-+-): r=6 ;\left(-o_{-}\right): r=4.5$.

Fig. 7 : Excitation spectra of solutions of the Eu ${ }^{\text {III }}$ triflate salt $5 \times 10^{-3} \mathrm{M}$ in BumimTf ${ }_{2} \mathrm{~N}\left(\lambda_{\mathrm{em}}=\right.$ $608 \mathrm{~nm}) .(-)$ : with TBACl, $r=6$; ( ๑ ) : with TBA-triflate, $r=6$. The sharp peak at 304 $\mathrm{nm}$ is due to the excitation light (608 $\mathrm{nm}$ is the second harmonic).

Fig. 8 : Emission spectra of solutions of the Eu ${ }^{\mathrm{III}}$ triflate salt $5 \times 10^{-3} \mathrm{M}$ in $\operatorname{BumimTf}_{2} \mathrm{~N}\left(\lambda_{\text {ex }}=\right.$ $464 \mathrm{~nm}) .(-)$ : with TBACl, $r=6 ;(-)$ ) : with TBA-triflate, $r=6$.

Tables, scheme and figures:

(7) (8)

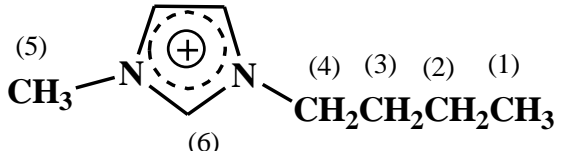

(6)

anion: Bumim

cation: $\left(\mathrm{CF}_{3} \mathrm{SO}_{2}\right)_{2} \mathrm{~N}^{-}\left(\mathrm{Tf}_{2} \mathrm{~N}\right)$

scheme 1

Table I : Decay behavior, lifetime values $(\mu \mathrm{s})$, relative intensities (\%) and $\mathrm{R}_{612 / 589}$ values for the Eu ${ }^{\text {III }}$-triflate salt in BumimTf ${ }_{2} \mathrm{~N}$ along the degassing/storage cycle (see text).

\begin{tabular}{|l|l|l|l|}
\hline $\begin{array}{l}\mathrm{t} \\
(\text { days })\end{array}$ & procedure & decay characteristics & $\mathrm{R}_{612 / 589}$ \\
\hline-1 & no degassing & $\begin{array}{l}\text { monoexponential } \\
\tau=159 \mu \mathrm{s}\end{array}$ & $<1$ \\
\hline 0 & degassing (I) & $\begin{array}{l}\text { bi-exponential } \\
\tau_{1}=643 \mu \mathrm{s}(19 \%) \\
\tau_{2}=1596 \mu \mathrm{s}(81 \%)\end{array}$ & 3.4 \\
\hline 6 & storage & monoexponential & n. d. \\
\hline
\end{tabular}




\begin{tabular}{|l|l|l|l|}
\hline & & $\tau=350 \mu \mathrm{s}$ & \\
\hline 13 & degassing (II) & bi-exponential & 3.4 \\
& & $\begin{array}{l}\tau_{1}=689 \mu \mathrm{s}(85 \%) \\
\tau_{2}=2556 \mu \mathrm{s}(15 \%)\end{array}$ & \\
& & monoexponential & n. d. \\
& & $\tau=681 \mu \mathrm{s}$ & \\
\hline 20 & storage & monoexponential & 3.4 \\
& & $\tau=545 \mu \mathrm{s}$ & \\
\hline
\end{tabular}

Table II : Lifetime values for the solutions of the $\mathrm{Eu}^{\mathrm{III}}$-triflate salt containing added TBACl.

\begin{tabular}{|l|l|}
\hline $\mathrm{r}=[\mathrm{TBACl}] /[\mathrm{Eu}]$ & $\tau(\mu \mathrm{s})$ \\
\hline 3.5 & 2038 \\
\hline 4.5 & 2060 \\
\hline 6 & 2560 \\
\hline 9 & 2760 \\
\hline
\end{tabular}

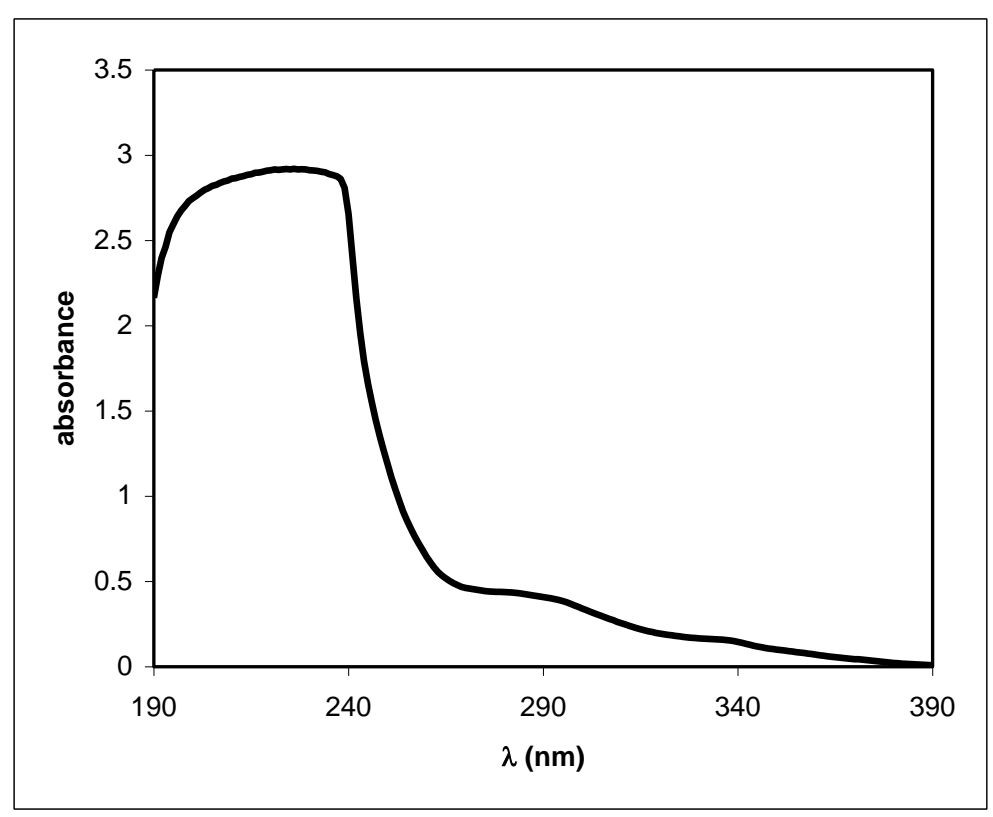

Figure 1 : Absorption spectrum of the BumimTf ${ }_{2} \mathrm{~N}$ batch used in this work (non degassed). 


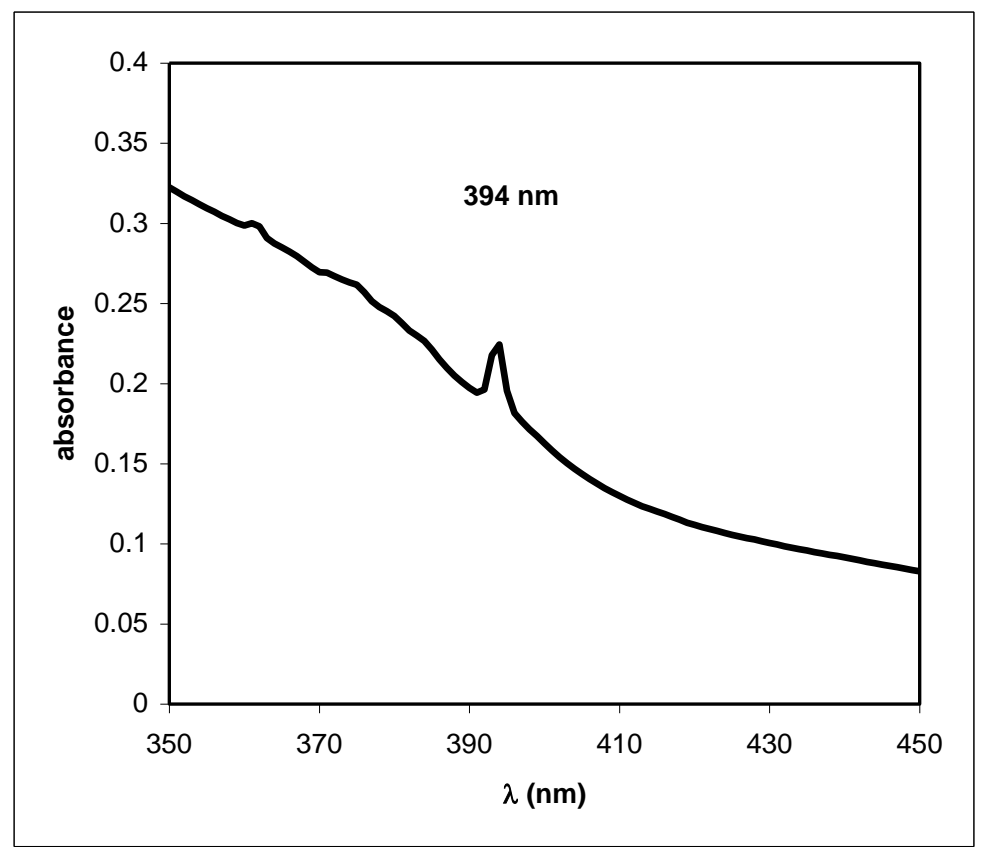

Figure 2 : absorption spectrum of the Eu ${ }^{\mathrm{III}}$ triflate salt $4 \times 10^{-2} \mathrm{M}$ in BumimTf $_{2} \mathrm{~N}$.

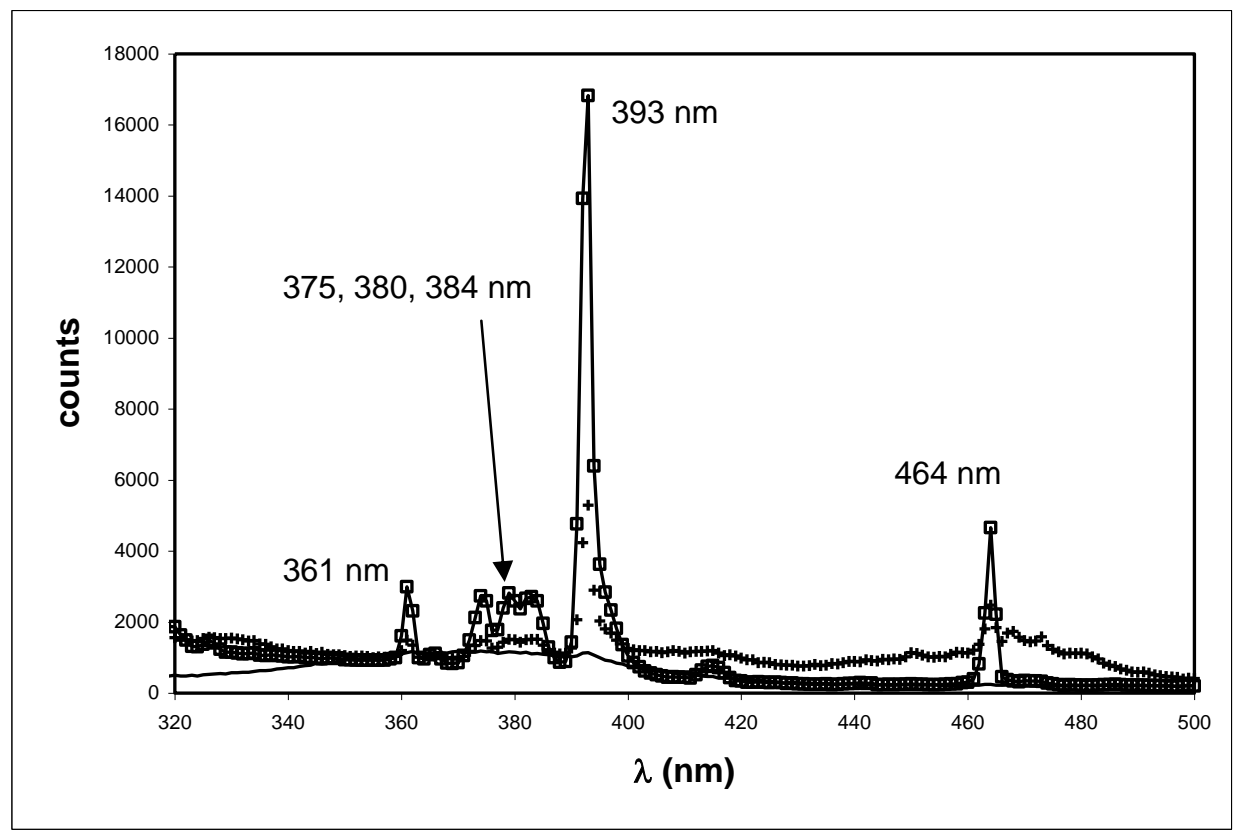

Fig. 3 : Excitation spectra of the Eu ${ }^{\mathrm{III}}$ triflate salt $5 \times 10^{-3} \mathrm{M}$ in BumimTf ${ }_{2} \mathrm{~N}$ during the degassing cycle. Emission wavelength $: \lambda=609 \mathrm{~nm}$. Solid line $: \mathrm{t}=-1$ day $;(-\square-): t=0$ day (procedure I) ; (-+-) : $\mathrm{t}=13$ days (procedure II). 


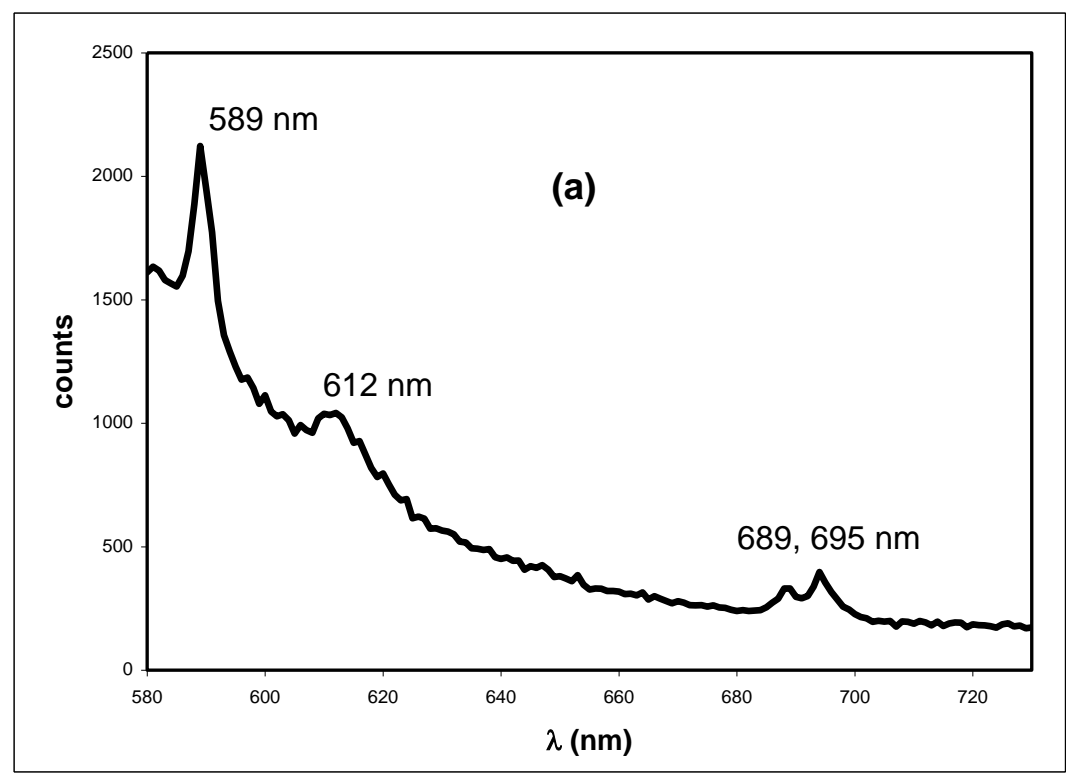

Figure 4a : Emission of the Eu ${ }^{\text {III }}$ triflate salt $5 \times 10^{-3} \mathrm{M}$ in BumimTf $_{2} \mathrm{~N}$ at $\mathrm{t}=-1$ day $($ see text and Table I). Excitation wavelength $: \lambda=394 \mathrm{~nm}$.

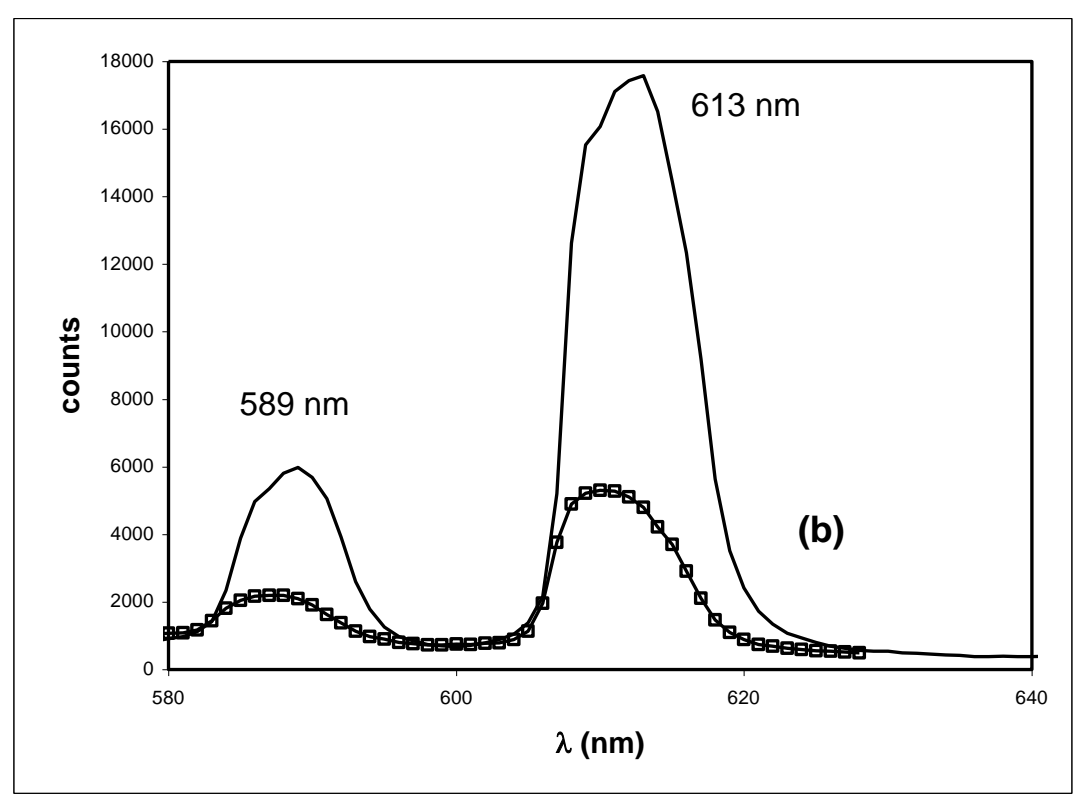

Figure $4 \mathrm{~b}$ : Emission of the Eu ${ }^{\mathrm{III}}$ triflate salt $5 \times 10^{-3} \mathrm{M}$ in BumimTf $_{2} \mathrm{~N}$ in function of the degassing procedure (see text and Table I). Excitation wavelength $: \lambda=393 \mathrm{~nm}$. Solid line :t $=0$ day $($ procedure $\mathrm{I}) ;(\mathrm{o}): \mathrm{t}=13$ days (procedure II). 


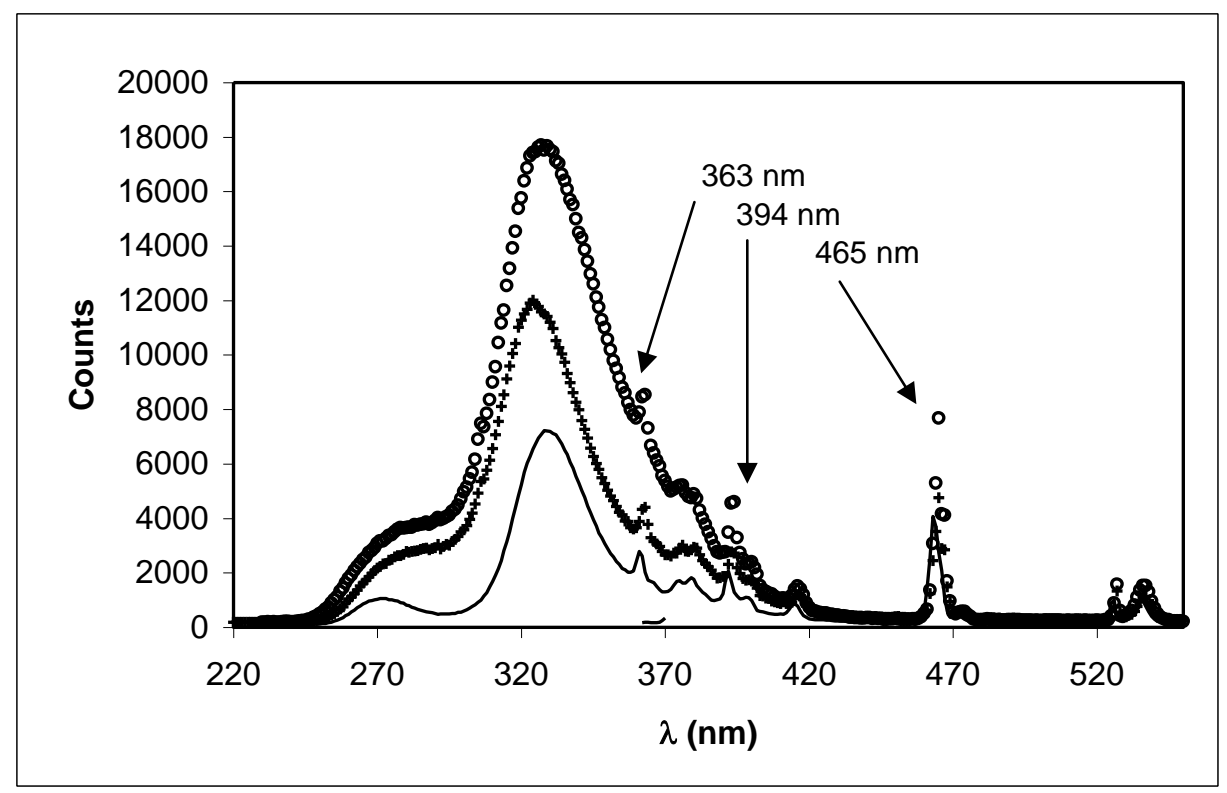

Figure 5: Excitation of the $\mathrm{Eu}^{\mathrm{III}}$ triflate salt $5 \times 10^{-3} \mathrm{M}$ in BumimTf $_{2} \mathrm{~N}$ containing TBACl. Emission at $\lambda=608 \mathrm{~nm}$. Solid line $: r=9 ;(-+-): r=6 ;(0): r=4.5$.

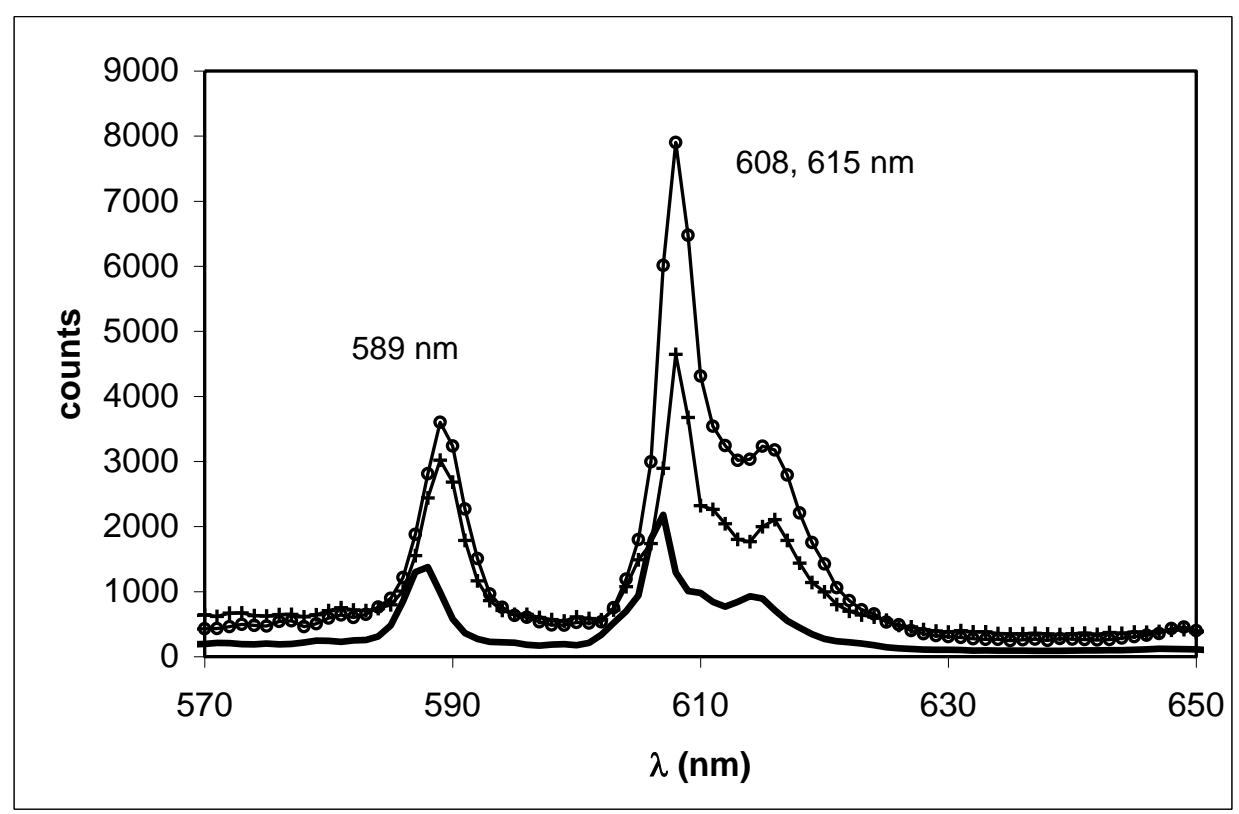

Figure 6: Emission of $\mathrm{Eu}^{\mathrm{III}}$ triflate salt $5 \times 10^{-3} \mathrm{M}$ in BumimTf $_{2} \mathrm{~N}$ containing TBACl. Excitation wavelength $: \lambda=464 \mathrm{~nm}$. Solid line $: r=9 ;(-+-): r=6 ;(-\circ-): r=4.5$. 


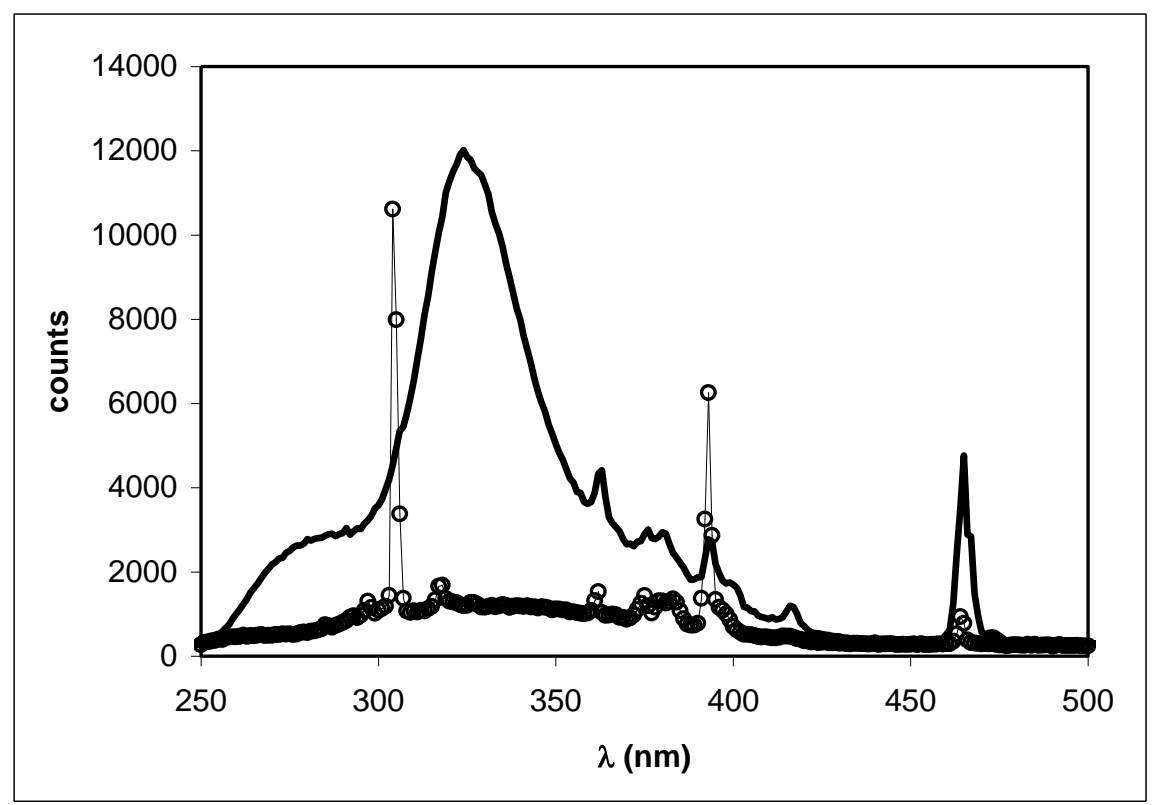

Fig. 7 : Excitation spectra of solutions of the Eu ${ }^{\text {III }}$ triflate salt $5 \times 10^{-3} \mathrm{M}^{\text {in } \text { BumimTf }_{2} \mathrm{~N}}\left(\lambda_{\mathrm{em}}=\right.$ $608 \mathrm{~nm}) .(-)$ : with TBACl, $r=6$; ( $\odot)$ : with TBA-triflate, $r=6$. The sharp peak at 304 $\mathrm{nm}$ is due to the excitation light (608 $\mathrm{nm}$ is the second harmonic).

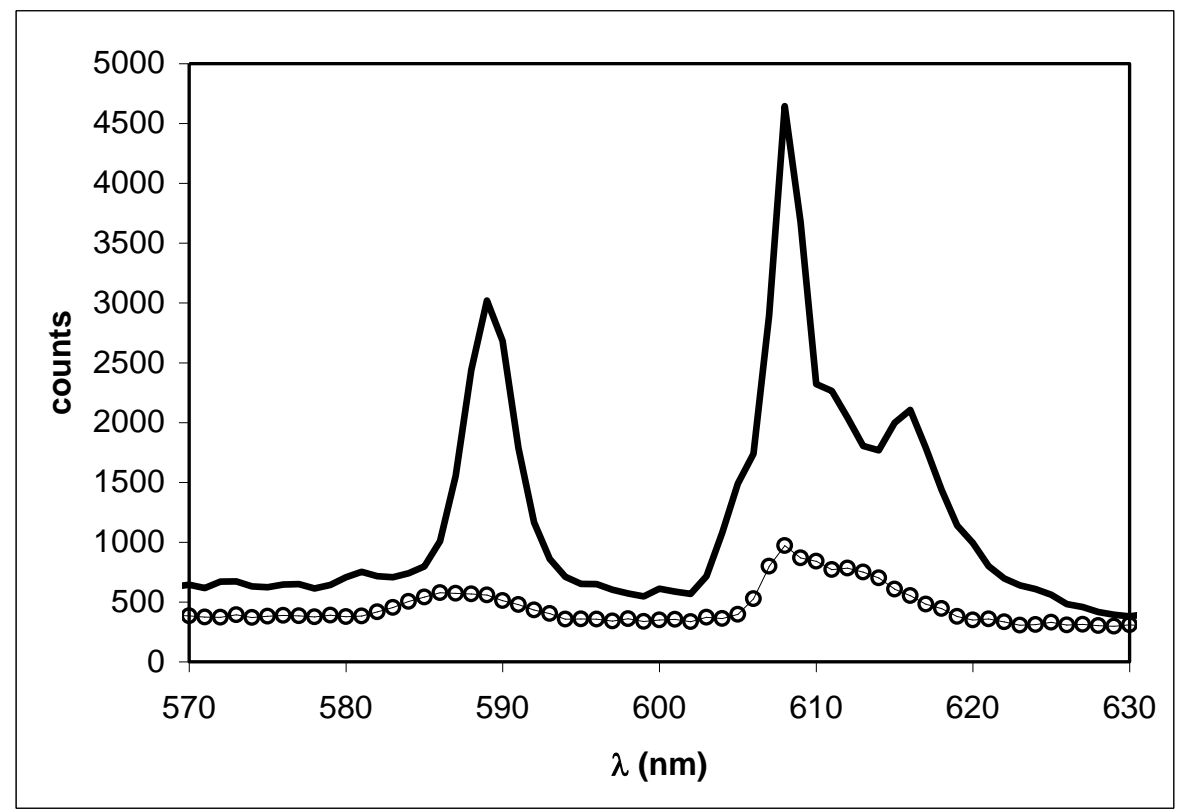

Fig. 8 : Emission spectra of solutions of the Eu ${ }^{\mathrm{III}}$ triflate salt $5 \times 10^{-3} \mathrm{M}$ in $\operatorname{BumimTf}_{2} \mathrm{~N}\left(\lambda_{\text {ex }}=\right.$ $464 \mathrm{~nm}) .(-)$ : with TBACl, $r=6 ;(-\odot)$ : with TBA-triflate, $r=6$. 
08/06/21 09:06 


\section{References}

${ }^{[1]}$ P. Wasserscheid, T. Welton, Ionic Liquids in Synthesis, Wiley-VCH: Weinheim, 2003.

${ }^{[2]}$ A. E. Visser, R. D. Rogers, J. Solid State Chem. 2003, 171, 109.

${ }^{[3]}$ D. Allen, G. Baston, A. E. Bradley, T. Gorman, A. Haile, I. Hamblett, J. E. Hatter, M. J. F. Healey, B. Hodgson, R. Lewin, K. V. Lovell, B. Newton, W. R. Pitner, D. W. Rooney, D. Sanders, K. R. Seddon, H. E. Sims, R. C. Thied, Green Chem. 2002, 4, 152.

${ }^{[4]}$ I. Billard, G. Moutiers, A. Labet, A. El Azzi, C. Gaillard, C. Mariet, K. Lützenkirchen, Inorg. Chem. 2003, 42, 1726.

${ }^{[5]}$ K. R. Seddon, J. Chem. Tech. Biotechnol. 1997, 68, 351.

${ }^{[6]}$ D. S. H. Wong, J. P. Chen, J. M. Chang, C. H. Chou, Fluid Phase Equilibria 2002, 194/197, 1089.

${ }^{[7]}$ J. L. Anthony, E. J. Maginn, J. F. Brennecke, J. Phys. Chem. B 2001, 105, 10942.

${ }^{[8]}$ K. R. Seddon, A. Stark, M. J. Torres, Pure Appl. Chem. 2000, 72, 2275.

${ }^{[9]}$ U. Schröder, J. D. Wadhawan, R. G. Compton, F. Marken, P. A. Z. Suarez, C. S. Consorti, R. F. de Souza, J. Dupont, New J. Chem. 2000, 24, 1009.

${ }^{[10]}$ C. D. Tran, S. H. De Paoli Lacerda, D. Oliveira, Appl. Spectrosc. 2003, 57, 152.

${ }^{[11]}$ W. T. Carnall, in Handbook on the Physics and Chemistry of Rare Earths: Non-metallic compounds I; North Holland: Amsterdam, 1979.

${ }^{[12]}$ L. C. Branco, J. N. Rosa, J. J. Moura Ramos, C. A. M. Afonso, Chem. Eur. J. 2002, 8, 3671 .

${ }^{[13]}$ S. G. Lee, J. H. Park, J. Kang, J. K. Lee, Chem. Commun. 2001, 1698.

${ }^{[14]}$ A. Nehlig, M. Elhabiri, I. Billard, A. M. Albrecht-Gary, K. Lützenkirchen, Radiochim. Acta 2002, 91, 37.

${ }^{[15]}$ Y. Haas, G. Stein, J. Phys. Chem. 1971, 75, 3677.

${ }^{[16]}$ J. -C. G. Bünzli, A. Milicic-Tang, in Handbook on the Physics and Chemistry of Rare Earths; Elsevier Science: Amsterdam, 1995.

${ }^{[17]}$ E. N. Rizkalla, G. R. Choppin, in Handbook on the Physics and Chemistry of Rare Earths; Elsevier Science: Amsterdam, 1991.

${ }^{[18]}$ A. Beeby, I. Clarkson, R. Dickins, S. Faulkner, D. Parker, L. Royle, A. de Sousa, J. Williams, M. Woods, J. Chem. Soc., Perkin Trans. II 1999, 493.

${ }^{[19]}$ R. M. Supkowski, W. deW. Horrocks Jr, Inorg. Chim. Acta 2002, 340, 44.

${ }^{[20]}$ D. Parker, J. Williams, J. Chem. Soc., Dalton Trans. 1996, 3613.

${ }^{[21]}$ G. R. Choppin, D. R. Peterman, Coord. Chem. Rev. 1998, 174, 283. 
${ }^{[22]}$ J. -C. G. Bünzli, G. R. Choppin, Lanthanide Probes in Life, Chemical and Earth Sciences: Theory and Practice, Elsevier: Amsterdam, 1989.

${ }^{[23]}$ O. A. Serra, L. C. Thompson, Inorg. Chem. 1976, 15, 504.

${ }^{[24]}$ C. Görller-Walrand, N. De Moitié-Neyt, Y. Beyens, J.-C. G. Bünzli, J. Chem. Phys. 1982, 77, 2261.

${ }^{[25]}$ W. deW. Horrocks Jr, V. K. Arkle, F. J. Liotta, D. R. Sudnick, J. Am. Chem. Soc. 1983, $105,3455$.

${ }^{[26]}$ I. Billard, K. Lützenkirchen, Radiochim. Acta 2003, 91, 285.

${ }^{[27]}$ G. Blasse, Structure and Bonding 1976, 26, 43.

${ }^{[28]}$ M. Bouby, I. Billard, A. Bonnenfant, G. Klein, Chem. Phys. 1999, 240, 353.

${ }^{[29]}$ I. Billard, A. Rustenholtz, L. Sémon, K. Lützenkirchen, Chem. Phys. 2001, 270, 345.

${ }^{[30]}$ I. Billard, E. Ansoborlo, K. Apperson, S. Arpigny, A. E. Azehna, D. Birch, P. Bros, H.

Burrows, G. R. Choppin, L. Couston, V. Dubois, T. Fanghänel, G. Geipel, S. Hubert, J. I. Kim, T. Kimura, R. Klenze, A. Kronenberg, M. Kumke, G. Lagarde, G. Lamarque, S. Lis, C. Madic, G. Meinrath, C. Moulin, R. Nagaishi, D. Parker, G. Plancque, F. Scherbaum, E. Simoni, S. Sinkov, C. Viallesoubranne, accepted in Appl. Spectrosc. 2003. 